Revista Destaques Acadêmicos, Lajeado, v. 10, n. 4, 2018. ISSN 2176-3070

DOI: http://dx.doi.org/10.22410/issn.2176-3070.v10i4a2018.2038

http://www.univates.br/revistas

\title{
PROJETO TEMA: APRIMORANDO O ENSINO NAS ENGENHARIAS POR MEIO DA EXTENSÃO UNIVERSITÁRIA
}

\author{
Fabrício Pretto ${ }^{1}$, Carlos Henrique Lagemann ${ }^{1}$, Evandro Franzen ${ }^{1}$, \\ Cristian Meinhardt ${ }^{1}$, Rebeca Jéssica Schmitz ${ }^{1}$, Natália Dal Más², \\ Raphael Perigo Weiand ${ }^{2}$, Maria Claudete Schorr ${ }^{1}$
}

\begin{abstract}
Resumo: O projeto de extensão Tecnologias Multidisciplinares Aplicadas (TEMA), amparado pela Universidade do Vale do Taquari - Univates, busca, por meio de ações extensionistas, disseminar o conhecimento científico e tecnológico, através de atividades práticas e lúdicas, em escolas de formação básica da rede pública e privada da região do Vale do Taquari. Em atividade desde 2016, o projeto conta atualmente com quatro áreas: Pontes de Espaguete; Desenvolvimento de Produto; Lógica de Programação e Robótica. As atividades do projeto dividem-se em: visita às escolas para apresentação oral do projeto e suas áreas de atuação; oficinas práticas, tanto nas escolas como na Instituição de Ensino Superior (IES) e, competições para integração dos estudantes. Através destas práticas, o projeto busca promover maior interação entre estudantes da IES e Educação Básica, despertando na comunidade externa o interesse pelas áreas das ciências exatas e tecnológicas, bem como contribuir para a formação do perfil do estudante de graduação, através das ações multidisciplinares, visto que a multidisciplinaridade é fundamental para a formação do indivíduo. O presente artigo tem como objetivo apresentar as atividades do projeto TEMA, divulgar os números relacionados à sua abrangência e apresentar os benefícios e oportunidades proporcionados pela extensão acadêmica aos estudantes de graduação. Durante os 3 anos de execução, o projeto contou com a participação de aproximadamente 480 alunos atuando como voluntários.
\end{abstract}

Palavras-chave: Projeto de extensão. Voluntários. Educação Básica.

\section{INTRODUÇÃO}

O processo de aprendizagem vem sofrendo mudanças dinâmicas no âmbito educacional recente. Diferentes metodologias e rotinas de ensino vêm

1 Professor - Universidade do Vale do Taquari - Univates

2 Aluno do Centro de Ciências Exatas e Tecnológicas - Universidade do Vale do Taquari Univates 
sendo implementadas, visando maximizar a obtenção da atenção do estudante, definindo um processo de construção de conhecimento eficiente e tangível. Preservar o aluno em estado de plena motivação mostra-se um dos desafios para instrutores na educação futura.

A utilização de tecnologia como ferramenta de apoio educacional é um dos alicerces na dispersão de conhecimento. Nos moldes comunicativos vigentes, as diferentes mídias apresentam-se em formatos interativos que, além de captar a atenção efetiva do usuário, mostram-se capazes de potencializar a comunicação entre os utilizadores, fortalecendo o trabalho em equipe. Sua praticidade e alcance por meio de jogos, redes sociais e softwares diversos são alguns dos fatores que, eventualmente, podem fazer da tecnologia um real aliado à educação tradicional.

As instituições de Educação Básica analisam estratégias diversificadas e atuais para a efetivação de um ensino motivante, interessante e que permita estabelecer uma ponte entre aluno e ensino. Essas estratégias promovem uma forma de buscar conhecimento com bases práticas, despertando o lado empírico do aprendizado no aluno. A utilização de tecnologias tem sido o apoio à instauração desse processo motivador, ampliando o leque de opções e diversificando as formas de realizar as atividades e apresentar os resultados.

Neste contexto, a extensão universitária tem como um de seus vieses a participação ativa e aproximação do ambiente acadêmico com a comunidade social externa em geral. O encontro entre pesquisa, aplicabilidade e situaçõesproblema cria um ambiente propenso ao afloramento de habilidades inerentes a cada estudante. A prática social mostra-se indispensável no procedimento, visto que a integração junto dos momentos de atividade proporciona incremento das habilidades nas áreas sociais, tanto para estudantes da Educação Básica, graduandos quanto bolsistas de extensão, além de pôr a prova o conhecimento concebido. Assim, o processo mostra-se benéfico para ambos os lados. $\mathrm{O}$ conhecimento apresenta-se palpável às mais diversas realidades, ampliando, assim, a visão de mundo dos estudantes.

Objetivando promover um melhor encontro entre ambiente universitário e comunidade escolar, o Projeto de Extensão TEMA - Tecnologias Multidisciplinares Aplicadas, da Univates, desenvolve ações que englobam alunos e professores de Graduação em dinâmicas práticas, dentre elas: palestras, competições e oficinas junto às escolas de Ensino Fundamental e Médio do Vale do Taquari e arredores. A aplicação prática dos conhecimentos configura-se como sustentáculo central do projeto, empregando conceitos fundamentais da área das engenharias - Física, Matemática e Lógica. Os campos desenvolvidos no projeto compreendem instâncias pertinentes à Lógica de Programação, Robótica, Pontes de Espaguete e Desenvolvimento de Produto.

O objetivo desse artigo é demonstrar a importância de promover aos estudantes das engenharias uma formação mais completa do ponto de vista profissional e pessoal, por meio das vivências e práticas extensionistas. 
Estabelecer conexão entre a academia e comunidade é fundamental para desenvolver o senso crítico e a comunicação, oferecendo uma formação integral.

Nesse documento será apresentada a estrutura do Projeto TEMA, a metodologia e prática de seus processos. O funcionamento de cada uma das 4 áreas singulares de atuação será abordado, bem como resultados obtidos durante as intervenções nas escolas nos anos de 2016 a 2018.

\section{EXTENSÃO UNIVERSITÁRIA}

Ampliar o ambiente de sala de aula tornou-se fundamental nas últimas décadas, uma vez que a forma de obter acesso à informação mudou. Proporcionar vivências realistas e próximas do mercado de trabalho enriquece o aprendizado e amplifica a retenção de conhecimento por meio da prática aliada à teoria. Neste capítulo serão apresentados duas abordagens: um entendimento genérico a respeito de extensão universitária; e como a extensão de uma Instituição de Ensino Superior tem sido abordada.

\subsection{Status Quo da extensão}

A extensão universitária visa integrar a universidade à comunidade na qual está inserida. Nunes e Silva (2001) destacam que a extensão universitária é uma espécie de ponte permanente entre a universidade e os diversos setores da sociedade. Destacam ainda que, ela funciona como uma via de duas mãos, em que a universidade leva conhecimentos e/ou assistência à comunidade, além de aprender com o saber dessas comunidades. Na extensão universitária, ocorre a troca de conhecimentos, seja ele entre estudantes da IES, da Educação Básica, bolsistas e professores. Além da troca de conhecimento, ocorre a troca de valores, pois a universidade, através da extensão, influencia e também é influenciada pela comunidade (SILVA, 1997). Através das ações difundidas pelos projetos extensionistas, oportuniza-se à comunidade em geral, ter acesso ao conhecimento de que a universidade é detentora.

As atividades de extensão são instrumentos eficazes para levar às pessoas que não frequentam os campi universitários, os conhecimentos produzidos pelos cursos ali oferecidos (NUNES; SILVA, 2001). Segundo Belhot (2005), o modelo institucional, isto é, aquele baseado essencialmente na transmissão e recepção da informação, ainda é muito utilizado em engenharia. Por outro lado, supõe-se que este modelo possa se alterar, face à velocidade de modificação e surgimento de novas informações. Nesse contexto, a extensão vai ao encontro à uma nova forma de difundir o saber, proporcionando aos que dela fazem uso, experiências e vivências práticas, tanto no âmbito social como no educacional. 


\subsection{Extensão na Univates}

Entende-se por projeto de extensão o conjunto de ações processuais contínuas, desenvolvidas de forma planejada, com objetivos e periodicidade definidos, que possuem caráter educativo, social, cultural, científico ou tecnológico (FORPROEX, 2007). Na Universidade do Vale do Taquari - Univates, a extensão é regida pela Pró-Reitoria de Ensino e Extensão Acadêmica.

A estrutura dos projetos busca a união de três sujeitos na construção do conhecimento (ALMEIDA; SAMPAIO, 2010; RABEL, 2012): estudantes, professores e comunidade. Os estudantes, sejam eles da graduação ou bolsistas, são os desenvolvedores da ação extensionista, cuja articulação principal é a do voluntariado acadêmico, criando um eixo de formação profissional e pessoal. Os professores desempenham o papel de orientadores, possibilitando a reflexão sobre a ação extensionista. A comunidade, entra como parceira na construção da extensão.

A esse respeito, Forproex (2006) desta que:

a dimensão crítica do conceito sala de aula, que deixa de ser somente o locus de produção teórico-abstrata para ser considerada como todo o espaço, dentro ou fora da universidade, onde se realiza o processo histórico social, vivido por diferentes atores. Professores e estudantes, confrontados com a realidade, são sujeitos do ato de aprender e de produzir conhecimentos. Nesse sentido, a relação entre o ensino e a extensão conduz a mudanças no processo pedagógico, na medida em que ambos constituem-se em sujeitos do mesmo ato: aprender. (p.23)

Vale destacar que, a flexibilização do currículo é importante para o desenvolvimento do estudante, com foco no voluntariado e na realização de atividades práticas, pois, sabe-se que na prática existem experiências de indissociabilidade inseridas em disciplinas, as quais possivelmente se constituem em motivação para incitar a sua disseminação de forma mais abrangente (FORPROEX, 2006; GONZATTI, DULLIUS, QUARTIERI, 2013).

De acordo com Garcia (2012):

A universidade é mesmo esse lugar propício para socializar, descobrir, construir conhecimento, mas, sobretudo, é espaço para dialogar sobre o conhecimento, para questioná-lo, para descobrir que ele pode não ser gerado somente pela universidade, mas também pelos atores que fazem parte do cotidiano desse espaço "privilegiado" para o desenvolvimento de saberes. (p.36)

Nesse contexto, espera-se dos projetos extensionistas, que ocorra maior interação entre discentes e docentes dos cursos das áreas envolvidas com a comunidade externa aos muros da universidade, possibilitando assim o 
desenvolvimento intelectual e a contextualização do ensino na educação para a carreira. A extensão contribui pondo em prática a parte técnica, como também, estimulando as relações interpessoais ao possibilitar o convívio direto dos estudantes da IES com a comunidade.

\section{ESTRUTURA PROJETO TEMA}

O projeto TEMA guia-se pela idealização de uma única óptica de abordagem e ensino que possibilite a união de diferentes áreas dentro das engenharias. Promove-se, assim, um ensino aplicado de Matemática, Física e Lógica em sala de aula. Em meio a isso, o encontro entre estes segmentos possibilita a multidisciplinaridade almejada pelo projeto, realizando, empiricamente, as atividades planejadas e engrenando os conhecimentos e habilidades adquiridos em movimento.

Segmentado em 4 áreas (Figura 1), o projeto possui 2 componentes adjacentes às Engenharias de Controle e Automação e Computação (Lógica de Programação e Robótica) e outros 2 (Desenvolvimento de Produto e Pontes de Espaguete) inerentes às Engenharias Civil, Mecânica e de Produção, cuja área de foco adentra nas necessidades estruturais e de processos.

Figura 1 - Estrutura do Projeto Tema

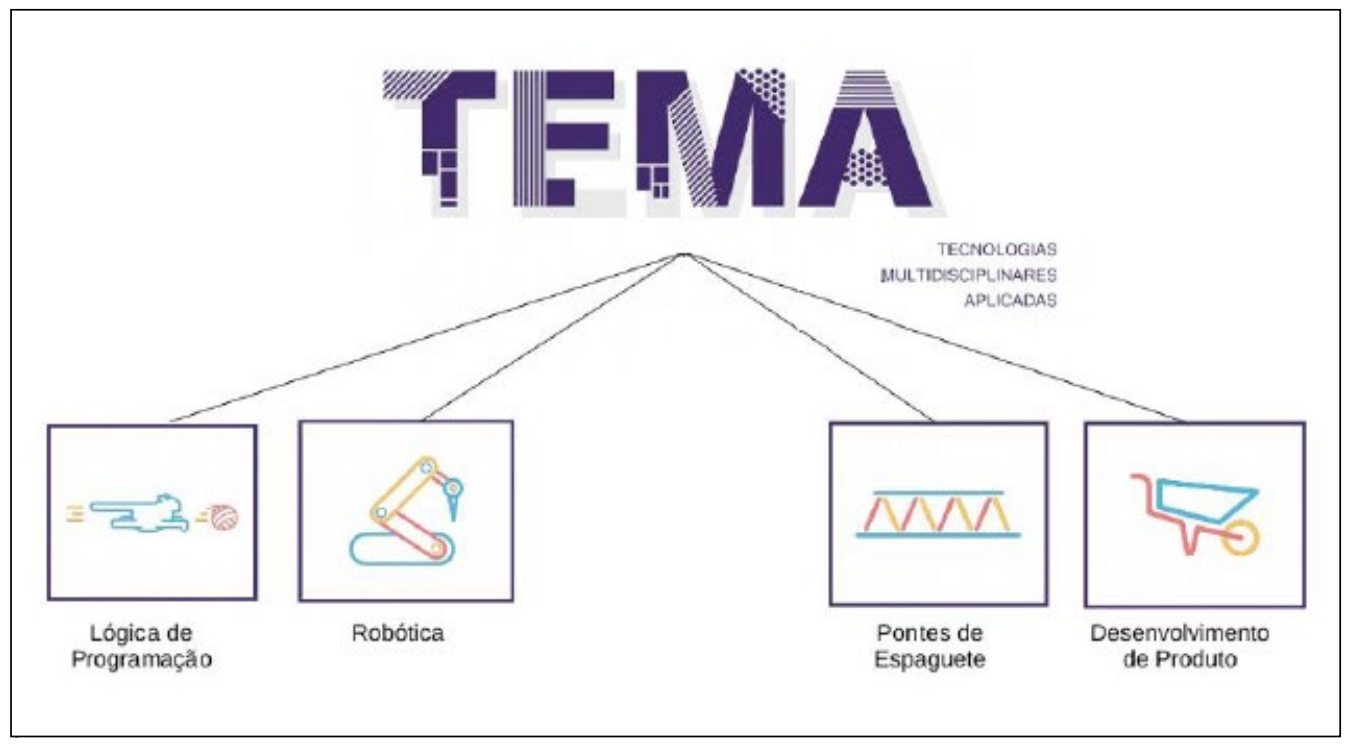

Fonte: Elaborado pelos autores (2018).

Cada segmento visa instigar o estudante a sair do papel e desenvolver, na prática, os ensinamentos e atividades propostos, incitando-o a desenvolver aspectos-chave como: concentração, comunicação em grupo, sede de saber e, não menos importante, a capacitação técnica do respectivo quadrante. 
O estudante tem de usar a inércia a seu favor; a proatividade e busca por conhecimento tem de estar em constante execução.

Nessa seção, serão expostas as atividades desenvolvidas pelo projeto TEMA em cada área de atuação, apresentando metodologia, ferramentas e sua prática em si.

\section{1 Área 1: Lógica de Programação}

Neste segmento, competências como imaginação, raciocínio lógico, superação de problemas e artifícios de criação são trabalhadas por intermédio do software Scratch 2.0, disponibilizado gratuitamente pelo MIT. Utilizandose apenas de computadores e o software em questão, estudantes de diferentes escolas e faixas etárias são instruídos a programar exemplos e situações in game (criação de animações, cenas interativas, manipulação de imagens, pseudoprogramação de jogos e programações mais específicas), configurando jogos educacionais. As atividades podem ser realizadas tanto nos laboratórios da IES quanto nas próprias escolas, devido à simples acessibilidade ao programa.

Visando avivar um processo de tirocínio prático no aluno, tendo como foco lógicas programacionais, soluções criativas e resolução de problemas, a área de programação oferece aos estudantes - de Ensino Fundamental e Médio - a chance de criar suas próprias histórias, podendo elas serem interativas ou não. O programa e a lógica aplicada propiciam ao aluno o poder de escolha, dispondo de uma gama de possibilidades e estruturas de elaboração amplas.

Devido a sua interface intuitiva e relativamente simples, a aprendizagem por trás do software Scratch não se mostra um problema. O aprendizado ocorre de maneira eficaz, prática e orgânica, tendo em vista que seus comandos e configurações ocorrem por meio de blocos operacionais autoexplicativos. As operações se seguem, majoritariamente, de forma intuitiva, sendo necessário pouco menos de um turno para capacitar e desenvolver nos jovens a aptidão para programar seus próprios filmes, animações e até jogos. $\mathrm{O}$ entendimento da lógica programacional ocorre de maneira inerente ao processo, dispondo os alunos em duplas e respeitando a familiaridade que cada integrante possui com o programa ao longo da realização das tarefas.

Após as oficinas realizadas, na IES ou no ambiente escolar, as escolas são convidadas a inscrever seus alunos para participar da Olimpíada de Informática da Univates, - Olinfu - evento realizado anualmente na IES. Escolas que já participaram de alguma oficina em algum momento ou que já utilizam a ferramenta Scratch, podem participar. Neste momento, alunos do sexto ano do Ensino Fundamental ao Ensino Médio de escolas dos vales do Taquari e Rio Pardo reúnem-se em uma competição saudável acerca de lógica de programação. O desígnio deste evento é o desenvolvimento de animações, jogos ou representações que correspondam às respostas de três questões elaboradas pela equipe do projeto. O tempo de duração da prova é de 4 horas e, 
durante este período, habilidades e conhecimentos práticos adquiridos durante as oficinas são postos à prova.

A Figura 2 ilustra a interface do software Scratch bem como o trecho de blocos de comando desenvolvido por um estudante do Ensino Fundamental (Nível 2) durante a Olimpíada de Informática no ano de 2018.

Figura 2: Interface do software Scratch 2.0.

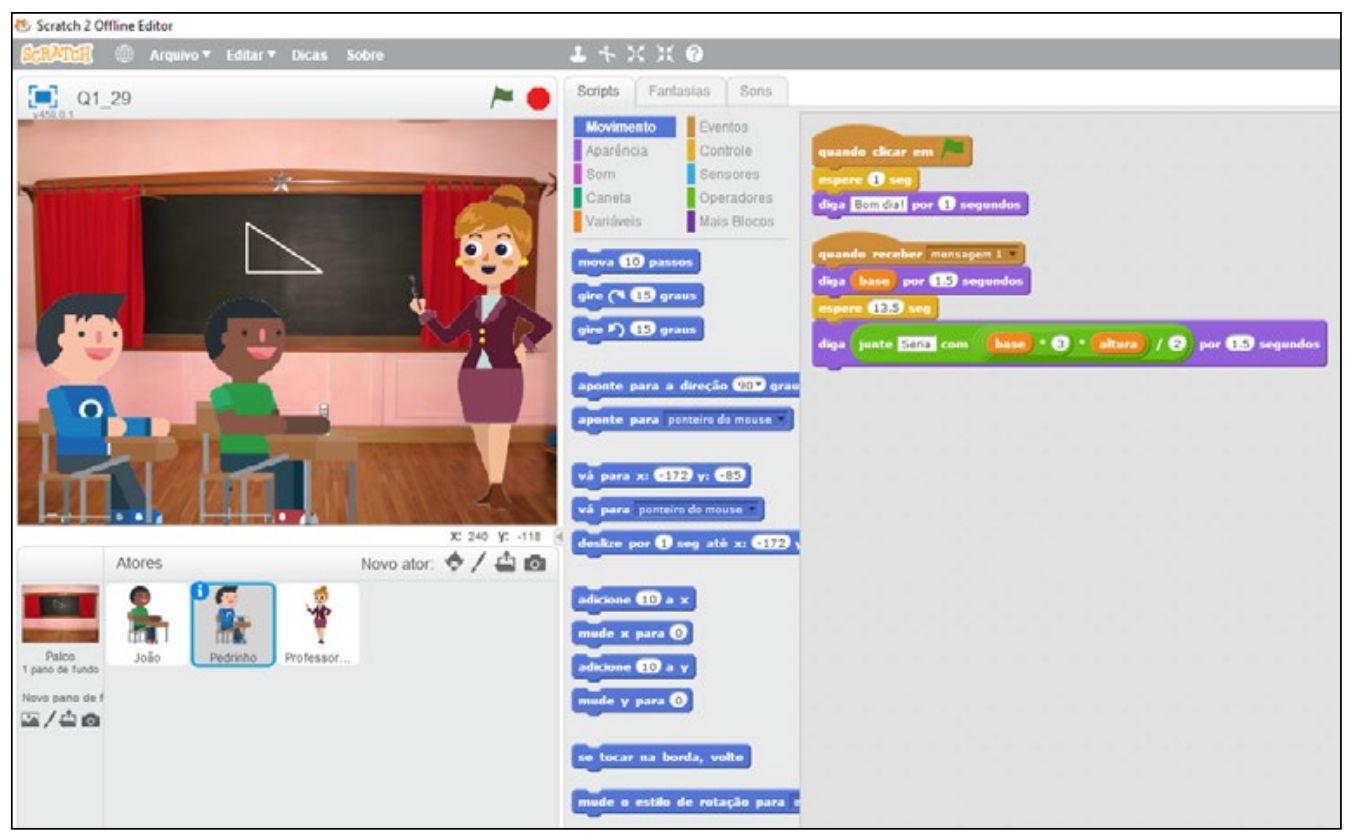

Fonte: Elaborado pelos autores (2018).

\section{2 Área 2: Robótica}

O segmento da robótica é responsável pela inserção do aluno em uma metodologia ampla, onde a aplicação estrutural e programacional devem atuar em conjunto, de forma harmoniosa. Notoriamente, trata-se de um campo que possui grande impacto nos jovens. A possibilidade de programar seu próprio robô, por meio dos materiais disponibilizados, é responsável por potencializar o anseio em aprender e aplicar do aluno. Processo este que gera satisfação e orgulho. Durante a etapa de divulgação nas escolas, a apresentação dos pequenos robôs em funcionamento causa euforia e animação dentre estes.

Para o desenvolvimento desta prática, faz-se o uso dos kits Lego Mindstorms EV3. Estes, por sua vez, possuem alta tecnologia aplicada, podendo realizar diversas tarefas - movimentação, cálculos, comparações, emissão de sons e imagens - simultaneamente. Todavia, seu entendimento é simples e direto, com rápida montagem e precisão na realização das atividades 
programadas. Mostram-se perfeitos para expor o potencial da área da robótica em uma oficina padrão. De maneira organizada e prática, a oficina se segue no seguinte molde: montagem, programação e teste. Focada cem por cento na prática, a atividade propicia aos alunos a organização e encaixe de peças; o processo lógico por trás da programação da máquina por meio de sensores e motores que, por sua vez, também possuem lógica pautada em blocos e, por fim, o teste dos robôs, que consiste, usualmente, em uma mini-prova de sumô realizada em uma pista própria da IES.

Durante o processo, a cooperação e o entendimento entre as duplas participantes mostram-se essenciais. Embora simples, o sistema de programação se distancia do óbvio em diversas ocasiões, fazendo com que, por vezes, os alunos deixem passar pequenos erros que dificultam o funcionamento ideal do protótipo. Não obstante, errar faz parte da caminhada de construção do conhecimento. Reconhecer seu erro é compreender o que o levou a ele, e essa é uma das mentalidades que se tenta propiciar com a prática.

Configuração correta de ações sequenciais, posicionamento e angulação de rotação de motores, equilíbrio ideal de peso e noções básicas de atrito; são estes alguns dos fatores que devem ser simultaneamente considerados pelos estudantes na montagem do EV3. As aplicações físicas, matemáticas e lógicas revezam-se e permeiam todos os processos da atividade.

Próximo ao término da oficina, é chegada a hora de testar os protótipos desenvolvidos. Utilizando-se do robô construído, customizado e programado exclusivamente por cada dupla, as equipes duelam entre si, observando resultados de funcionamento e rendimento. Conforme os rounds passam, ajustes são realizados por intermédio dos alunos, visando se adequar melhor à atividade e tornando seu robô mais competitivo para batalhar novamente. O processo é estimulante e contínuo. A Figura 3 contempla o processo de programação e montagem de robô sendo realizado pelos estudantes. 
Figura 3: Processo de programação via software LEGO MINDSTORMS.

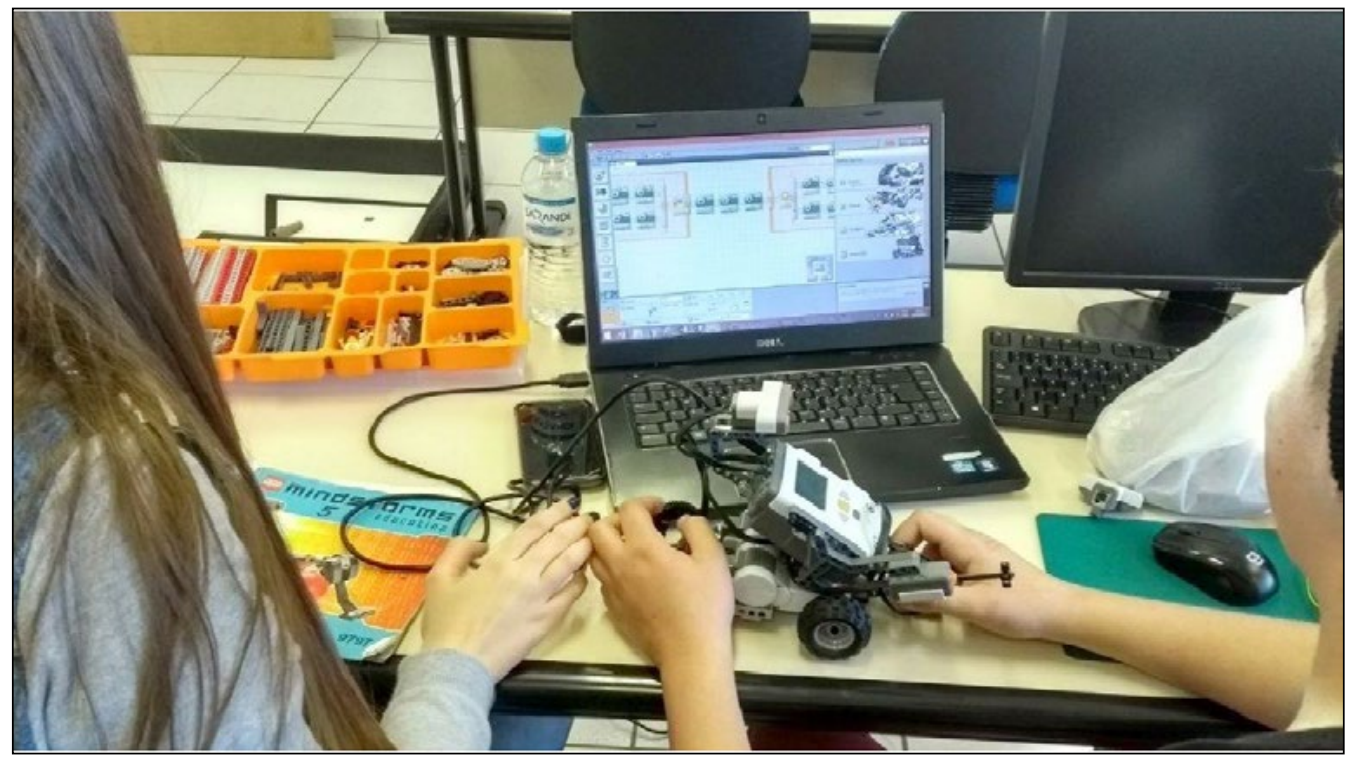

Fonte: Elaborado pelos autores (2018).

\section{3 Área 3: Pontes de espaguete}

A concepção, elaboração e experiência destrutiva de pontes treliçadas, constituídas apenas de espaguete e cola epóxi, mostra-se um desafio para estudantes de arquitetura e engenharia mundo afora. Prática com início há mais de 4 décadas, a realização da competição ocorre tradicionalmente no Brasil e no mundo, tendo como recorde global um exemplar Húngaro, capaz de suportar mais de $666,3 \mathrm{~kg}$. A Univates, por sua vez, proporciona a atividade anualmente desde 2013 até os dias atuais e, detendo um recorde próprio de $131 \mathrm{~kg}$, vem colhendo bons resultados.

Nos cursos de graduação, a prática busca instigar no aluno o processo de autonomia e organização. A aplicação de conhecimentos teóricos acerca de resistência de materiais, elaboração e execução de projetos estruturais e solucionamento de situações problema representam alguns dos obstáculos a serem contornados para a execução do intento.

Antecedente à construção, um estudo e levantamento de relações estruturais, projeto da ponte, estimativa de carga da ponte bem como avaliação sobre opções de tipos de treliças devem ser pensadas com clareza pelo grupo. Por sua vez, a ponte deve obedecer a certos padrões pré estipulados referentes a altura (no máximo $50 \mathrm{~cm}$ ), largura (de 5 a $20 \mathrm{~cm}$ ) e peso (máximo $900 \mathrm{~g}$ ), tendo, ainda, que vencer um vão livre de 1 metro de comprimento. 
As pontes são edificadas com massa espaguete, marca Barilla, tipo Spaghettoni, número 7, que possui diâmetro e comprimento médios, respectivos, de $1,8 \mathrm{~mm}$ e $25,4 \mathrm{~mm}$. A escolha do espaguete, bem como marca e tipo, segue um padrão mundial na modalidade, sendo a massa comercializada em embalagens contendo porções de $500 \mathrm{~g}$. Dados como: resistência à tração e compressão tal como o módulo de elasticidade destes fios de espaguete são de conhecimento padrão entre a comunidade do segmento. Em sua confecção, podem ser utilizadas colas epóxi do tipo resina (de marcas como Araldite e Poxipol) e do tipo massa (por exemplo, das marcas Durepoxi, Polyepox e Poxibonder).

Junto de sua estrutura, canos de PVC para água fria (de $20 \mathrm{~mm}$ de diâmetro externo e $20 \mathrm{~cm}$ de comprimento) são dispostos nas extremidades inferiores da ponte, visando proporcionar maior apoio entre estas e as faces superiores (planas e horizontais) da dupla de blocos colocados no mesmo nível. Após construída, deve-se submeter a ponte a um teste de carregamento estático. Para sua realização, uma barra de aço de construção de $8 \mathrm{~mm}$ de diâmetro e comprimento igual à largura da ponte deve ser posicionada ao centro, participando de sua estrutura; a barra deve ser disposta na mesma altura e direção do cano de $\mathrm{PVC}$, de maneira a ser perpendicular ao comprimento da ponte. O propósito da barra é transmitir à ponte a carga aplicada por seu intermédio.

Em termos de Escola Básica, mais precisamente o Ensino Médio, o estudo e confecção de pontes busca aproximar os alunos de conceitos físicos relacionados à resistência de materiais e execução de projeto, conhecimentos triviais nos estudos de engenharia. Durante a prática, alunos são instruídos, de maneira mais sucinta, a estruturar uma ponte com um projeto já efetuado (não cabem cálculos e quantitações do sistema aos participantes). Desta forma, os estudantes de ensino básico constroem pontes similares às confeccionadas por estudantes da graduação e competições mundo afora, diferenciando-se apenas por seu tamanho em escala reduzida.

Para a realização das oficinas, conta-se, voluntariamente, com a colaboração de estudantes das graduações relacionadas, buscando efetivar uma melhor transmissão do conhecimento. Assim, o desenvolvimento dos alunos - tanto de graduação quanto de Ensino Médio - ocorre de forma simultânea, potencializando-se e expandindo.

A Figura 4 demonstra pontes de espaguete concebidas por estudantes de Ensino Médio do Vale do Taquari. 
Figura 4 - Pontes de espaguete construídas pelos estudantes de ensino médio.

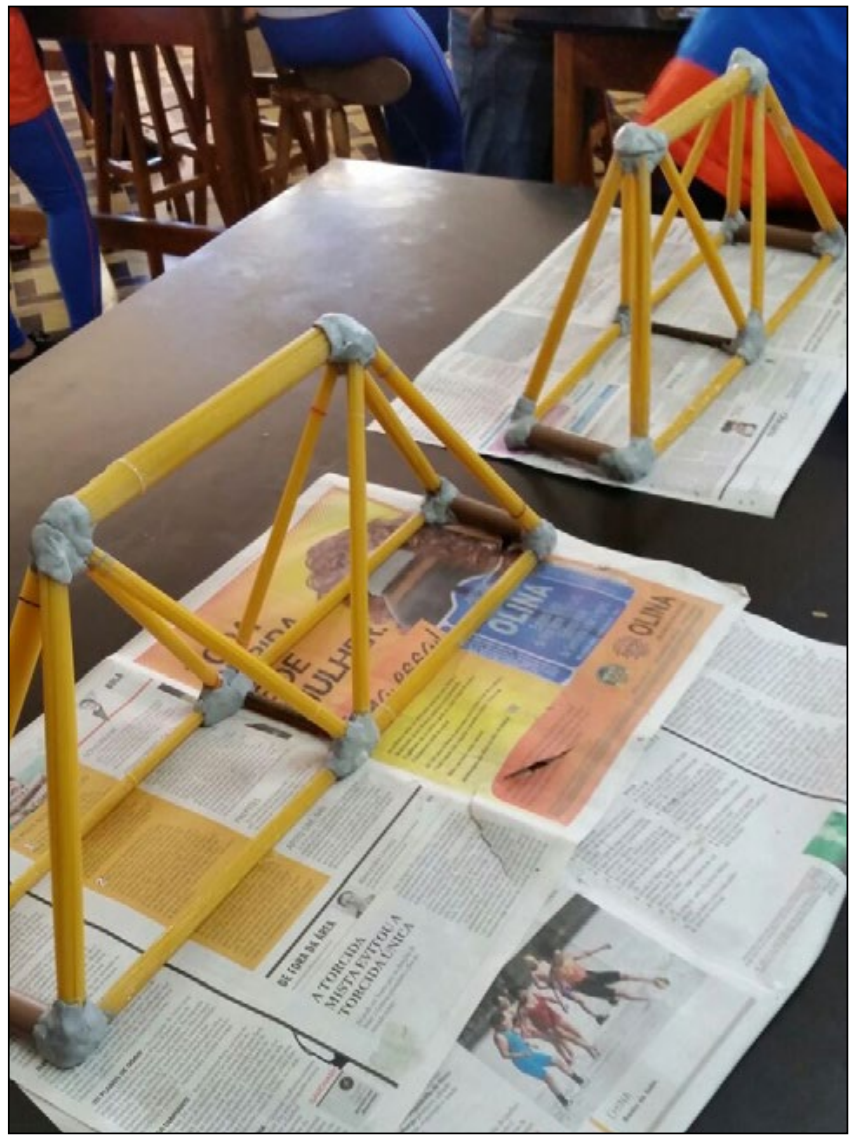

Fonte: Elaborado pelos autores (2018).

\section{4 Área 4 - Desenvolvimento de produto}

Neste segmento do projeto, utilizando-se de materiais e conceitos não convencionais, os estudantes são instigados a inovar na elaboração e construção de produtos. O intuito é desenvolver neles noções básicas de criação, projeto, avaliação do processo de fabricação, montagem e testes práticos. Em meio ao processo, conceitos físicos são discutidos para a montagem de um melhor produto.

No campo em questão, o equipamento a ser desenvolvido é um carrinho de mão; ferramenta amplamente utilizada para transporte de cargas, tendo como força motriz a ação humana. Dentre suas especificações, o carrinho deve apresentar: no mínimo uma roda, uma haste que será empunhada pelo condutor, uma estrutura que permita que o participante a ser transportado se sente dentro do carrinho com as pernas e braços cruzados (teste estático - 
inicial), e que este consiga permanecer estático sem a mediação de outrem. $\mathrm{O}$ passageiro, por sua vez, deve pesar de $60 \mathrm{~kg}$ a $100 \mathrm{~kg}$ e, caso esta norma não esteja de acordo, este deverá carregar consigo pelo percurso o número de sacos de areia necessários para que a especificação seja cumprida (cada qual pesando $5 \mathrm{~kg})$.

O carrinho é concebido visando suportar uma carga limite de $100 \mathrm{~kg}$, que é averiguada através do teste estático. Após sua confecção, o carrinho é utilizado para o cumprimento de um circuito de obstáculos desconhecidos pelos estudantes. $\mathrm{O}$ vencedor é dado por aquele que realizar o percurso no menor tempo, mantendo o carrinho operante e transportando efetivamente sua dupla. Caso alguma parte do produto se desprenda, esta deve ser carregada por um dos integrantes até a linha de chegada; todas peças devem cruzar a chegada.

A Figura 5A apresenta uma dupla realizando o percurso de competição. A Figura 5B trata-se de uma oficina de capacitação para estudantes voluntários do projeto.

Figura 5: (A) - Modelo de pista de prova dos carrinhos de mão. (B) - Oficina de capacitação de voluntários e estudantes das engenharias.

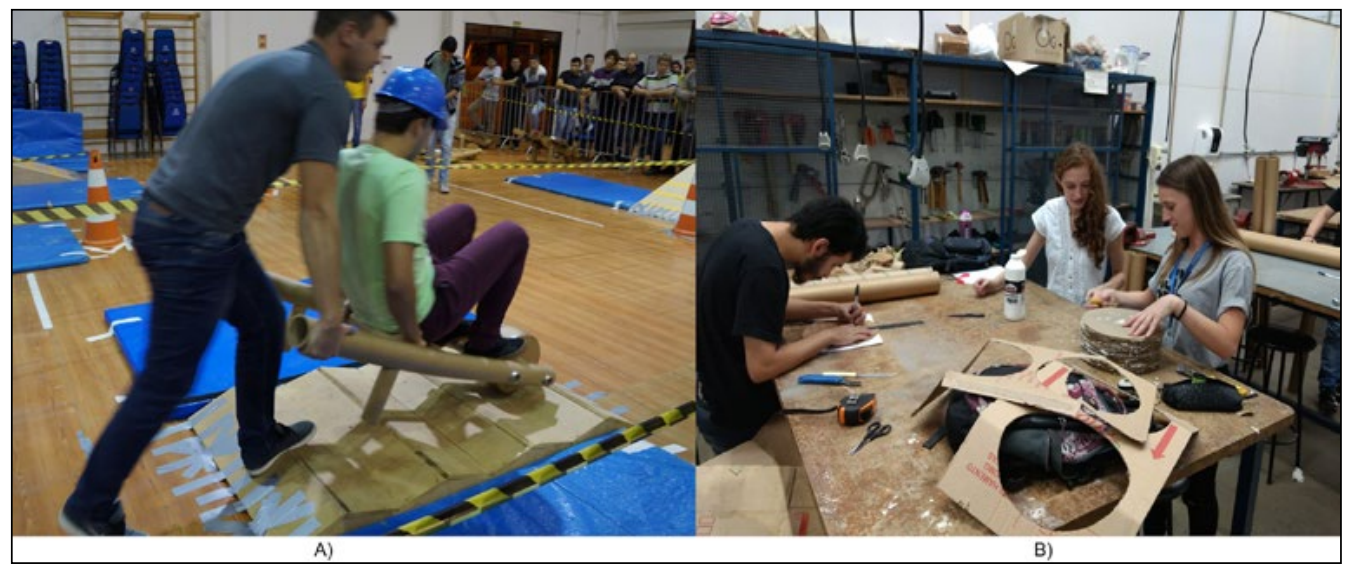

Fonte: Elaborado pelos autores (2018).

A partir das normas estabelecidas pelo projeto, não é permitida a utilização de protótipos que ultrapassem a marca dos $8 \mathrm{~kg}$. Por outro lado, não há especificações quanto a seu formato e dimensões. O intuito é fazer com que o estudante busque maneiras não habituais - e, no melhor dos planos, inovadoras - de projetar e arquitetar um carrinho que funcione de forma efetiva no transporte de pequenas e grandes cargas. Contanto que as regras citadas sejam seguidas, o processo de criação é livre e nele estão implícitos diversos conceitos físicos, tais como estática, força e momento. 
Em suma, o produto a ser projetado deve ser de fácil manobragem e alta resistência estrutural, visto que deverá suportar cargas até 10 vezes maiores que a sua. Tendo em mente o incentivo à pesquisa dos conceitos fundamentais de Engenharia, sugere-se às equipes que avaliem com esmero os seguintes itens: estabilidade do carrinho; perfis estruturais com maior resistência; condição de manobragem; força-peso transmitida ao condutor; superfície de apoio ao aluno transportado e configuração das rodas. Reflexões estas que buscam maximizar os resultados.

Em sua elaboração, faz-se o uso de pedaços de papelão diversos, sendo sua espessura máxima (para chapas ou tubos) de $5 \mathrm{~mm}$, não podendo o tubo ultrapassar o diâmetro de 100mm. É consentido a utilização de grampos e colas, caso se almeje confeccionar um perfil de chapa específico, sendo também possível utilizar óleos e graxas para facilitar no rolamento da(s) roda(s). Qualquer outro tipo de material não listado não possui implementação permitida. Deve ser possível observar a constituição do carrinho e seus materiais; portanto, este não deve ser pintado.

\section{METODOLOGIA}

O projeto de extensão TEMA tem como um de seus alicerces a comunicação e o relacionamento com instituições de Educação Básica do Vale do Taquari e arredores. A equipe de extensão dispõe de professores ligados à área das ciências exatas, tais como: Engenharia de Produção, Engenharia da Computação, Engenharia Civil e Engenharia Mecânica. Deste modo, todas as ações aqui descritas possuem, de alguma forma, ligação e foco de atividade com a área de formação de cada membro constituinte.

A elaboração das ações passa por seis atos, sendo eles:

Ato 1: Engajamento de voluntários, organização de material, admissão de bolsistas e divulgação de projeto. Todas ações deste ato são de caráter administrativo. Entrevistas, pautadas nas habilidades necessárias, são realizadas findando recrutar bolsistas capazes de atuar nas diversas áreas da extensão. Além do processo do recrutamento, a confecção de materiais didáticos, PDFs, arquivos, figuras, vídeos e apresentações é realizada neste período de organização. De forma diversificada, a divulgação do projeto passa pelas salas de aula, redes sociais e listas de e-mail - de cursos ligados - de forma que o acadêmico sinta-se convidado a participar como voluntário de extensão. O processo também passa pela Rádio Univates, TV Univates, Jornal Interno Univates e Jornais externos à Universidade, possuindo ampla divulgação. Todas atividades e regulamentos competitivos são preparados, avaliados e checados previamente pelo grupo de professores do projeto.

Ato 2: Aproximação com as escolas. Tarefas de cunho comunicativo ocorrem, majoritariamente, no primeiro semestre do ano, buscando agendar apresentações do projeto, oficinas e encontros com as instituições de ensino. A 
comunicação comumente utilizada é feita via e-mail, podendo também ocorrer por telefone ou, eventualmente, de forma pessoal.

Ato 3: Apresentações em escolas. Apresentações são maneiras breves e eficazes de sintetizar o caráter de atuação do projeto dentro de suas áreas. Desta forma, as ações ligadas ao projeto são expostas à comunidade por meio de recursos audiovisuais, vídeos, demonstrações e oratória convencional; com base no que fora elaborado no Ato 1.

Ato 4: Oficinas. Fase do projeto em que leva-se o aluno à experiência prática; a vivenciar a ciência. Nesta etapa, a contribuição exercida pelos bolsistas e voluntários mostra-se intrínseca ao projeto. As oficinas realizadas nas escolas são pautadas entorno dos estudantes, tanto da graduação quanto da Educação Básica, tendo como foco a aprendizagem de maneira prática, experimental e vívida. De maneira instigante, visa-se levar conhecimentos da área das engenharias ao estudante de ensino básico. As oficinas ocorrem de modo a contemplar as áreas de conhecimento vinculadas ao projeto TEMA, elencadas anteriormente.

Ato 5: Competições integradoras. Tendo em mente o cumprimento de um dos objetivos particulares do projeto, o evento Technology Day é realizado anualmente, servindo de palco para competições que englobam todas as atividades práticas do projeto até o momento de sua realização. $\mathrm{O}$ evento é, por característica, uma reunião de todas as ações centrais do projeto TEMA. Este momento é o reflexo do trabalho realizado ao longo do ano, onde equipes sendo elas concebidas durante as oficinas ou formadas na instituição - reúnemse na Univates em prol do evento. $\mathrm{O}$ foco do evento, bem como seu nome sugere, é voltado para a área das ciências exatas, e assim o são seus projetos e desafios. Por de trás do evento, valores como relacionamento interpessoal, espírito competitivo e trabalho em equipe são desenvolvidos e potencializados, tanto nos alunos da educação básica, quanto nos alunos da IES. A prática do convívio social cria raízes positivas na comunidade, trazendo consigo as bases científicas do evento.

Ato 6: Avaliação das ações. Por intermédio da tríade: análise implementação - avaliação, nessa etapa, o projeto de extensão objetiva avaliar as ações propostas. Integralmente, todas as ações do projeto implementam um processo de avaliação via questionário ou entrevista aos alunos, tendo, assim, um feedback da atividade realizada. Melhorias, incrementos e cortes são efetuados a partir das críticas da comunidade. Junto ao questionário, a opção de comentários abertos é utilizada de forma a fornecer recomendações à equipe. $\mathrm{O}$ processo avaliativo mostra-se fundamental pois identifica necessidades na comunidade; as avaliações realizadas servem como subsídio para identificação do nível de conhecimento sobre o tema abordado, bem como a satisfação em ter participado dessa capacitação.

Os ápices de energia encontram-se nos atos 3 e 4. Por energia, refere-se ao esforço realizado pelas partes constituintes do projeto: bolsistas, professores, 
voluntários e alunos do Ensino Básico nas atividades em questão. Todas ações e atos realizados no projeto - apresentações, oficinas e planejamentos contribuem para a realização do Technology Day. Evento este que proporciona integração e aproximação da comunidade com o meio científico-acadêmico.

Realizado anualmente na IES, o Technology Day apresenta-se como uma atividade de cunho comunitário, integrando estudantes das graduações, ensino básico e corpo social. O evento, tipicamente, ocorre na semana acadêmica das engenharias da Univates, participando do fechamento do Congresso de Ciência e Tecnologia do Vale do Taquari (CCTEC). Em 2018, o espetáculo serviu de palco para atividades como: Competição - percurso e sumô - de Robótica, Campeonato de League of Legends (eSports), Competição de Pontes de Espaguete, Desafio de Desenvolvimento de Produto, Aparato de Proteção ao Ovo (APO), Olimpíada de Informática da Univates (Olinfu), Competição de Pontes de Palito de Picolé, Desafio Kit Mola e Desafio das Taludes. A aplicação do conhecimento científico é evidenciado pelas diversas modalidades entre competidores do evento, podendo ser acompanhada em tempo real pelos espectadores. Sua realização, além de proporcionar um momento prático de competições e aplicação de conhecimento, ainda oportuniza uma aproximação com a comunidade, mantendo-a a par dos projetos acadêmicos desenvolvidos durante o ano pelas áreas das engenharias e arquitetura.

\section{RESULTADOS}

A duração do projeto TEMA é de doze meses, compreendendo o período de Março a Fevereiro. Todo plano de ação é idealizado antes do início das atividades e, executado de acordo com o cronograma estipulado. Todas as atividades realizadas pelo projeto são catalogadas e contabilizadas, para efeito de controle e acompanhamento para posteriores análises e melhorias. Dentre as atividades constam: apresentação do projeto e suas áreas nas escolas da região; oficina prática da área escolhida; competição entre diferentes níveis ao final das oficinas; participação do Technology Day, conforme mencionado no Capítulo 3.

Destas atividades, destacamos o engajamento de estudantes da graduação, como voluntários, em atividades executadas pelo projeto. Em média, entre os anos de 2016 e 2018, cento e sessenta (160) estudantes atuaram como voluntários, em algum ato do projeto TEMA, durante as ações executadas. Este dado mostra-se relevante para o dimensionamento da área de atuação e efetividade do projeto, proporcionando a estudantes de diferentes cursos das engenharias a oportunidade de se auto desenvolverem. A extensão atua como conexão entre a sala de aula e a comunidade externa aos muros universitários. Em suas ações os estudantes de diferentes cursos e semestres têm a oportunidade de experimentar práticas de convívio, exposição ao público, demonstração de saberes, aquisição de novos conhecimentos e ao mesmo tempo compartilhar o que sabem, tudo por meio do contato estabelecido com pessoas, nesse contexto do projeto, estudantes da Educação Básica. 
Ao ser voluntário de projeto de extensão, o estudante pode atuar, contribuindo e favorecendo-se dos benefícios citados em diversos momentos. No projeto TEMA, por exemplo, previamente à visita às escolas, realiza-se uma oficina de capacitação, o que possibilita aos acadêmicos, de quaisquer cursos da IES, obterem capacitação para auxiliar os bolsistas e atender às demandas vivenciadas a cada oficina. Cada capacitação possui duração de um turno e o processo ocorre de maneira satisfatória, visto que seus resultados compreendem todas as ações efetuadas em sala de aula. $\mathrm{O}$ voluntário chega ao fim do processo entendendo plenamente as questões abordadas na oficina, sendo capaz de sanar eventuais dúvidas e auxiliar nas práticas. Nesse exemplo evidencia-se que a possível falta conhecimento e experiência em alguma área de conhecimento pode ser suprida dentro do próprio projeto. Posterior a capacitação e aquisição desse conhecimento, o estudante voluntário passa a atuar como facilitador e promotor do conhecimento. Por vezes se depara com situações que não são de seu conhecimento, exigindo rápido contorno para obter a melhor solução para o momento.

O projeto tem visitado em média, anualmente, dez (10) municípios da região do Vale e arredores e, atendido cerca de vinte (20) escolas por ano. Ao longo de seus três anos de ações, o projeto atendeu mais de quatro mil e duzentos (4200) estudantes da Educação Básica.

A Figura 6 apresenta um gráfico que demonstra os dados analisados nas edições de 2016, 2017 e 2018. 
Figura 6 - Números das atividades realizadas pelo projeto TEMA.

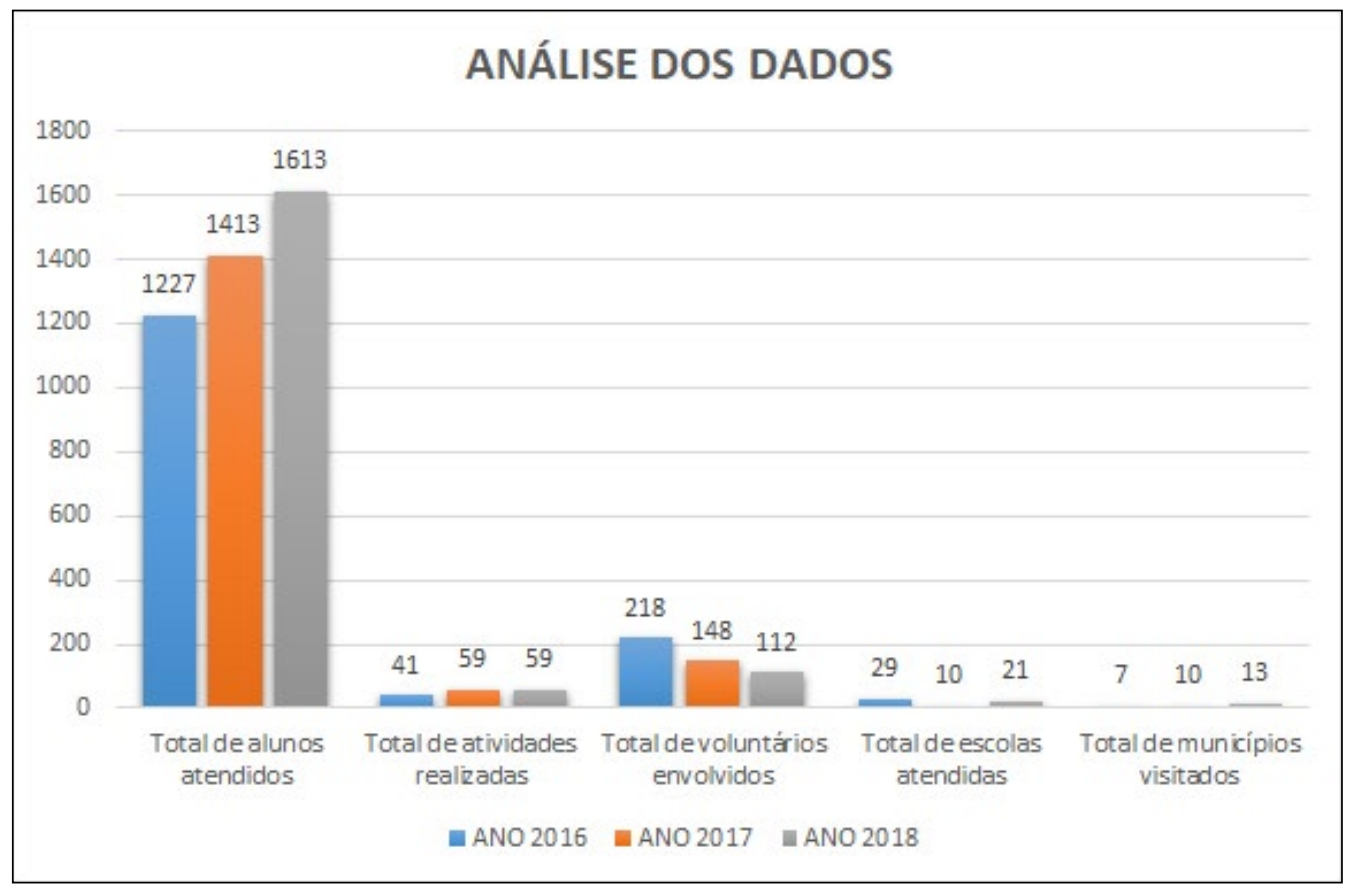

Fonte: Elaborado pelos autores (2018).

Conforme mencionado no Capítulo 4, ao final de cada ação, os participantes são convidados a responderem um questionário avaliativo sobre a atividade. Desta forma, podemos mensurar o quanto as ações são proveitosas. O questionário possui quatro perguntas e um campo aberto para comentários, como mostra a Figura 7.

A seguir, será demonstrado as respostas ao questionário de uma oficina de Lógica de Programação, realizada no município de Travesseiro, em Junho de 2018. No exemplo apresentado, não evidenciamos resultados negativos e ruins, muito pelo contrário, obteve-se um posicionamento extremamente positivo dos participantes. Esse tem sido o padrão de qualidade para as ações do projeto TEMA. 
Figura 7: Modelo de questionário aplicado após as intervenções.

\section{IIIUNIVATES}

LNIVEREADE DO VAL. DO TAQL ABI - INAVATS

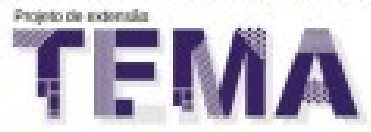

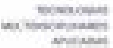

Escola:

Data da ação:

O que você achou da peática desenvolvida?

( ) Muito boa

( ) Boa

( ) Regular

( ) Ruim

Foi possivel realizar alguma relação entre algum conteúdo trabalhado $\mathrm{cm}$ sala de aula, com a oficina realizada?
( ) $\mathrm{Sim}$
( ) Um pouco
( ) Nảo

Você indicaria a oficina para seus colegas?
( ) $\operatorname{Sim}$
( ) Nào

Como você vê a contribuiçăo do projeto para sua formaçăo?
( ) Muito útil
( ) Ùtil
( ) Regular
( ) Nåo contribuiu

Deixe aqui um breve comentário sobre a atividade:

Fonte: Elaborado pelos autores (2018). 
Figura 8 : Análise das atividades desenvolvidas.

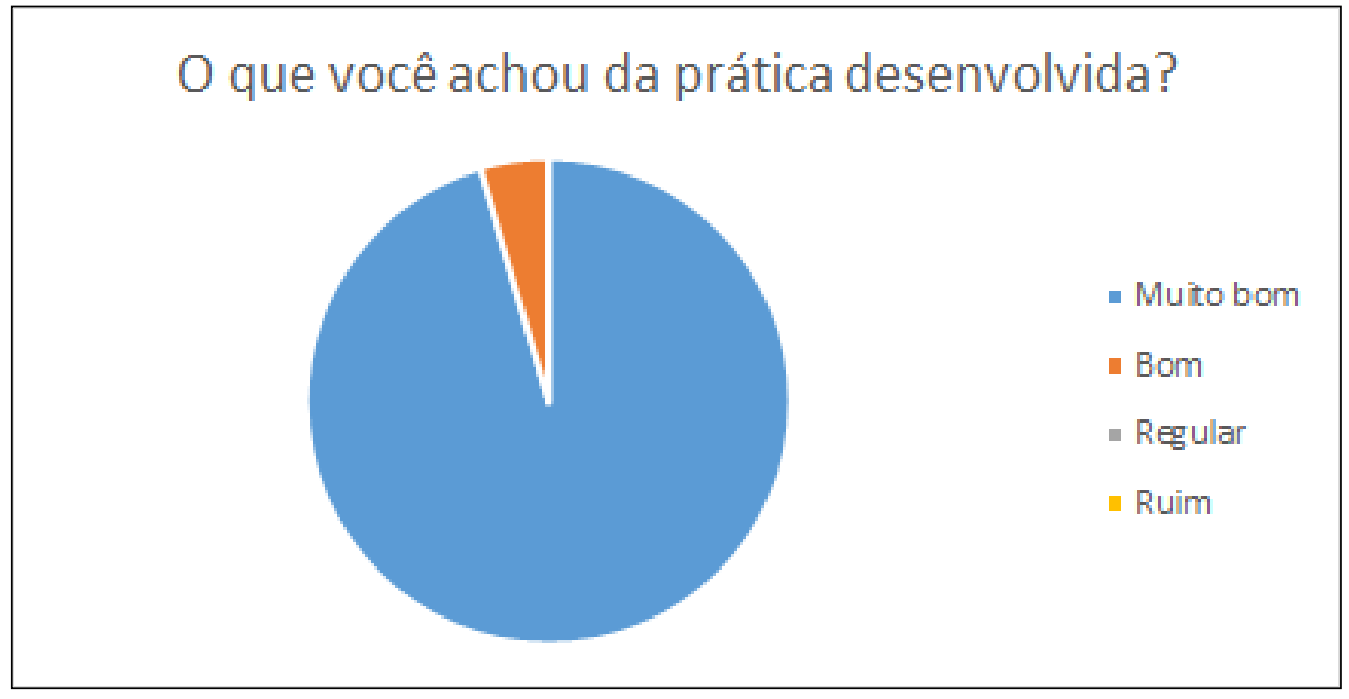

Fonte: Elaborado pelos autores (2018).

\section{CONSIDERAÇÕES FINAIS}

Este artigo teve por finalidade demonstrar a gama de conhecimentos que podem vir a ser agregados aos estudantes de graduação por meio de ações práticas, bem como o desenvolvimento destes dentro das quatro áreas que o projeto TEMA permeia. Frisou-se, também, o valor contido na inserção do graduando em um ambiente com professores da IES, alunos e professores da Educação Básica, possibilitando a construção de habilidades não somente de cunho técnico, mas também comunicacionais e sociais.

Atuando de forma experimental em conjunto com as quatro áreas, abrese um leque de oportunidades para que o estudante conheça a si e segmentos de sua área de atuação futura. As vivências extensionistas possibilitam o aprimoramento de competências inerentes à profissão do estudante, proporcionando a este bases para uma melhor formação e atuação profissional.

Tendo em vista os resultados apresentados no Capítulo 5, o projeto atingiu adequadamente seus objetivos, oferecendo capacitação para mais de 110 estudantes, em média, durante os três anos de atuação, por meio de práticas e vivências extensionistas. Acredita-se que parte destes adquiriram, de fato, conhecimento para si e tiveram a oportunidade de partilhar em sala de aula durante a realização das oficinas.

Nas avaliações realizadas ao final de cada atividade, pode-se perceber que as ações têm sido úteis e muito satisfatórias para os estudantes. A forma como os conhecimentos são abordados dentro do projeto, encanta os estudantes 
da Educação Básica. O uso de tecnologia aplicada como apoio ao processo de desenvolvimento do raciocínio lógico tem se mostrado atraente, juntamente às atividades lúdicas e práticas, que são característica do projeto TEMA.

\section{REFERÊNCIAS}

ALMEIDA, Luciane Pinho de; SAMPAIO, Jorge Hamilton. Extensão Universitária: aprendizagens para transformações necessárias no mundo da vida. Revista Diálogos: Construção Conceitual de Extensão e outras reflexões significativas. Brasília, v. 14 p. 33-41, 2010.

BELHOT, Renato Vairo. A didática no ensino da engenharia. In: CONGRESSO BRASILEIRO DE ENSINO DE ENGENHARIA, COBENGE, 23, 2005, Campina Grande. Anais. Campina Grande: UFCG, 2005. p. 1 - 12.

FORPROEX. Fórum de Pró-Reitores de Extensão das Universidades Públicas Brasileiras. Extensão Universitária: Organização e Sistematização. Belo Horizonte: Coopmed, 2007. Disponível em < https://www.ufmg.br/proex/renex/images/ documentos/Organizacao-e Sistematizacao.pdf >. Acesso em: 26 nov. 2016.

FORPROEX. Indissociabilidade Ensino-Pesquisa-Extensão e a Flexibilização Curricular: uma visão da extensão. Porto Alegre: Ufrgs, 2006. Disponível em: $<$ https://www.ufmg.br/proex/renex/images/documentos/Indissociabilidade-eFlexibilizacao.pdf >. Acesso em: 26 nov. 2016.

GONZATTI, Sonia Elisa Marchi; DULLIUS, Maria Madalena; QUARTIERI, Marli Teresinha. O potencial da extensão para a formação profissional. In: SÍVERES, Luiz (org). A extensão universitária como princípio de aprendizagem. Brasília: Liber Livro, 2013. p. 223-244. Disponível em: <http:/ / unesdoc.unesco.org/ images/0023/002320/232083por.pdf >. Acesso em: 26 nov. 2016.

NUNES, La Ferreira Nunes Ana Lucia de Paula Ferreira; SILVA, Maria Batista da Cruz. A extensão universitária no ensino superior e a sociedade. Mal-estar e Sociedade, Barbacena, p.119-133, dez. 2001.

RABEL, Luciane Coelho. Os Sujeitos envolvidos no fazer da extensão Universitária. In: SÍVERES, Luíz (Org.). Processos de Aprendizagem na Extensão Universitária. Goiânia: Editora da PUC Goiás, 2012. p. 37-52. 